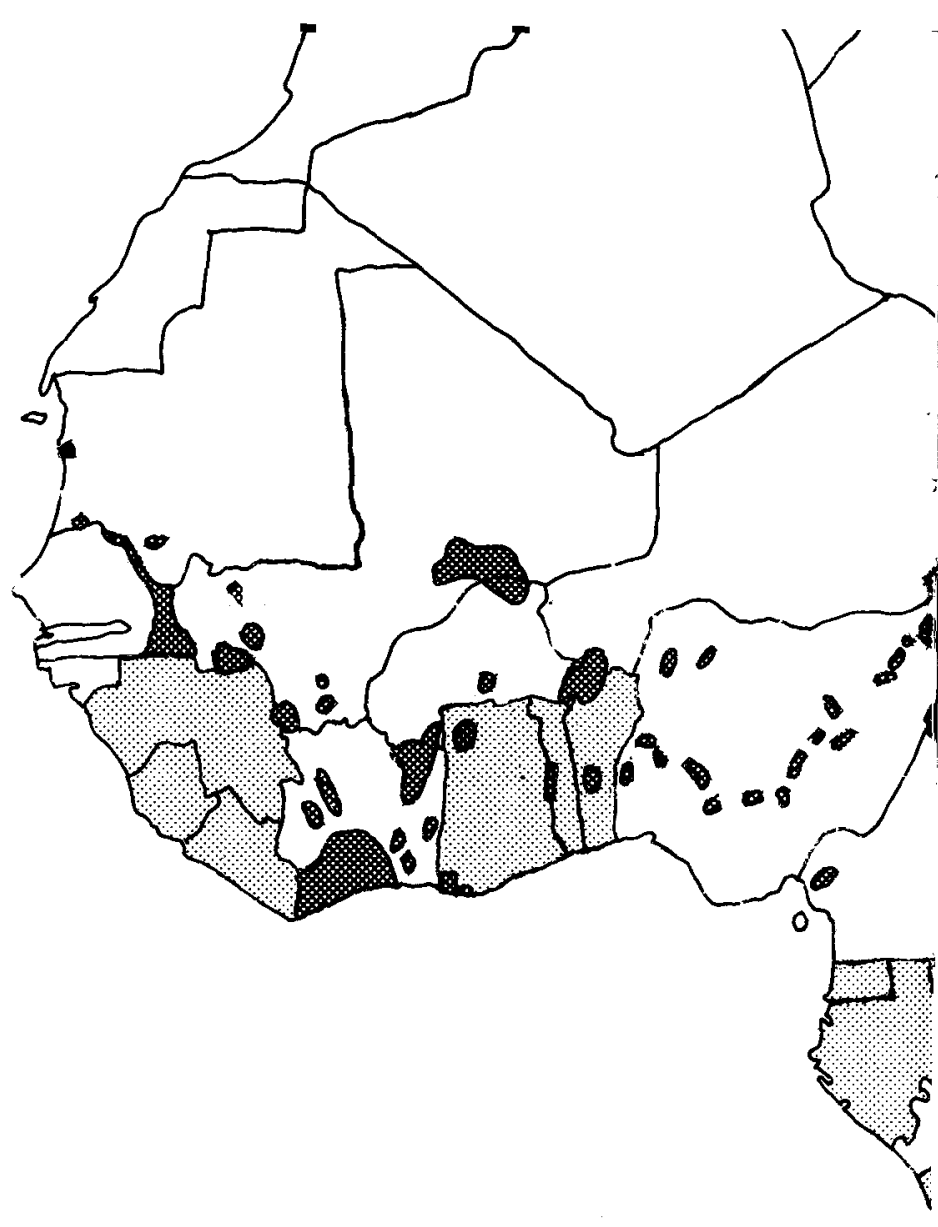

\title{
African Elephant Survey
}

After the first six months of the IUCN/WWF elephant project, Dr Iain Douglas-Hamilton, head of the African section, has compiled this map, representing the extent of current knowledge about the distribution of Loxodonta africana. His accompanying report says,

'The continental picture is still very far from complete, and in most cases we cannot yet hazard a guess at elephant numbers within a country. We can, however, summarise our current knowledge of the elephants' distribution on a map. We have marked their ranges even when they occur only occasionally or at very low densities, and have indicated areas where we lack information, or where elephants are definitely absent. The map is very much a first draft, and we hope that readers will send us amendments and/or corrections.'

Reports will be issued regularly and are obtainable from World Wildlife Fund, PO Box 40075, Nairobi, Kenya. 


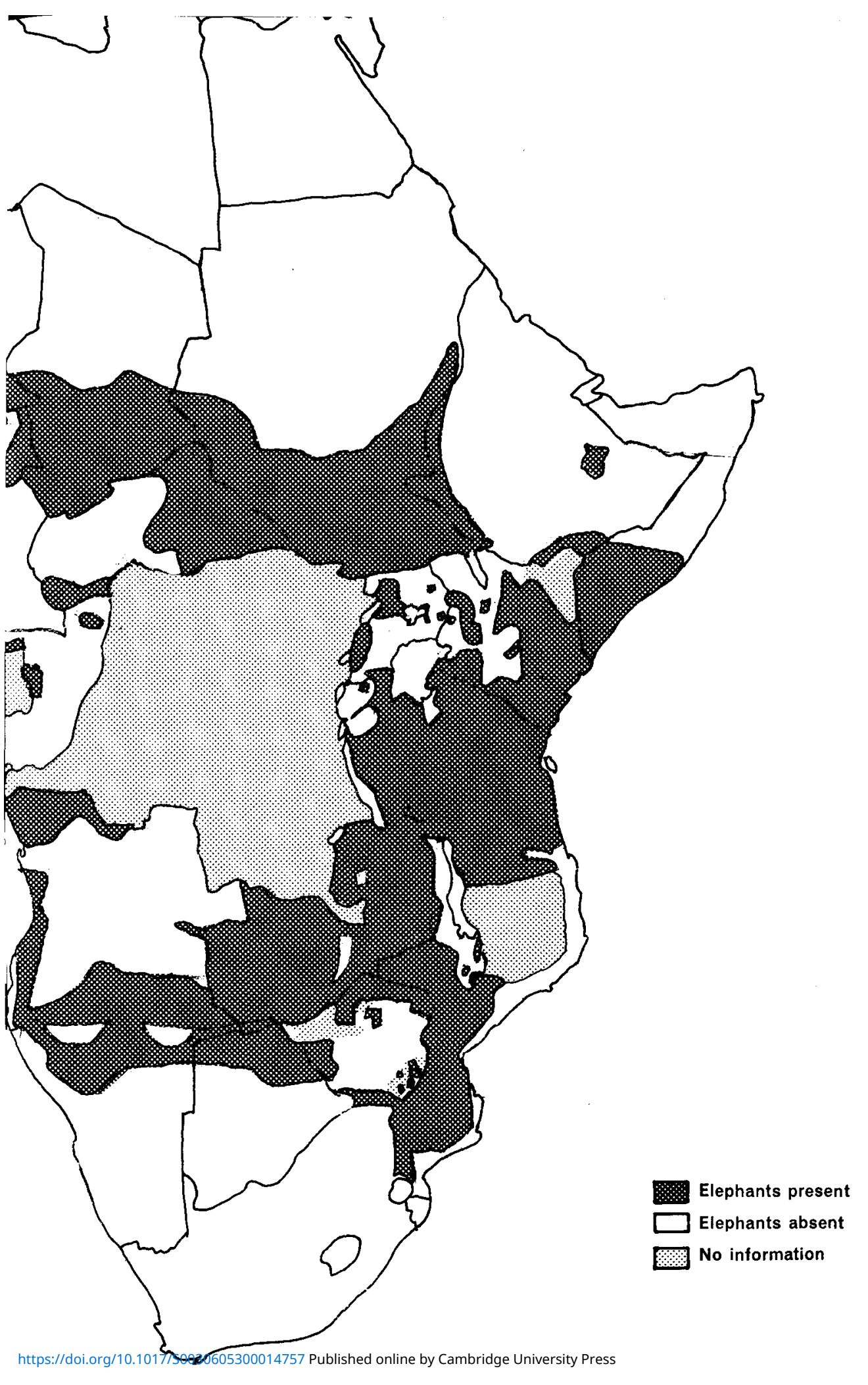

